\title{
Feasibility study of a low-temperature geothermal power plant for multiple economic scenarios
}

\author{
Sarah Van Erdeweghe ${ }^{\mathrm{a}, \mathrm{c}}$, Johan Van Bael ${ }^{\mathrm{b}, \mathrm{c}}$, Ben Laenen ${ }^{\mathrm{b}}$, William D'haeseleer ${ }^{\mathrm{a}, \mathrm{c}, *}$ \\ ${ }^{a}$ University of Leuven (KU Leuven), Applied Mechanics and Energy Conversion Section, Celestijnenlaan 300 - box \\ 2421, B-3001 Leuven, Belgium \\ ${ }^{b}$ Flemish Institute for Technological Research (VITO), Boeretang 200, B-2400 Mol, Belgium \\ ${ }^{c}$ EnergyVille, Thor Park, Poort Genk 8310, B-3600 Genk, Belgium
}

\begin{abstract}
Deep-geothermal energy is a renewable energy source which provides a constant heat flux to the earth surface. If this heat is used properly, the geothermal power plant might serve as a baseload plant. However, geothermal well drilling costs are high, so the economic feasibility is not always secured. This is especially the case for low brine temperatures, which are common in NW Europe. In this paper, we will investigate the feasibility of a low-temperature geothermal plant for multiple economic scenarios. Whereas, in the literature, the focus is often on the influence of heat source conditions and environmental parameters, we focus on the economic parameter assumptions (electricity price, discount rate, lifetime, availability factor and well drilling costs). The design of the heat exchangers and the air-cooled condenser are optimized together with the operating conditions based on a thermo-economic optimization algorithm. The net present value (NPV) is the objective function. We find that the same geothermal project might be profitable (NPV=11.63MEUR) or loss-making (NPV=-9.91MEUR), depending on the economic situation. Good economic conditions are an incentive to build a more expensive ORC which generates a high electrical power output, whereas in bad conditions, a cheap ORC must be chosen which produces less electricity.

Keywords: feasibility study, low-grade geothermal energy, ORC, thermo-economic optimization
\end{abstract}

\footnotetext{
${ }^{*}$ Corresponding author

Email address: william.dhaeseleer@kuleuven.be (William D'haeseleer)
} 


\section{Introduction}

Organic Rankine Cycles (ORCs) have widely been studied in the literature. Some recent thermoeconomic studies have been performed by, among others, Imran et al. [1, Garg et al. 2], Zhang et al. [3, Xi et al. 4] and Budisulistyo et al. [5].

5 Imran et al. [1 have studied the performance of a basic, a recuperative and a regenerative ORC for a geothermal source temperature of $160^{\circ} \mathrm{C}$ and a mass flow rate of $5 \mathrm{~kg} / \mathrm{s}$. The injection temperature is limited to $70^{\circ} \mathrm{C}$. The results have been found by a Pareto-front optimization of the exergy efficiency (maximizing) and the specific investment cost (minimizing). They have concluded that the basic ORC has the lowest specific investment cost for an exergy efficiency smaller than $45 \%$, whereas the regenerative ORC is the most suitable for an exergy efficiency higher than $45 \%$.

Garg et al. 2] have performed a thermo-economic optimization of sub 500kWe ORCs for waste-heat and solar heat sources, considering various working fluids. They have used the specific investment cost as the objective function. The authors have found that, from the 19 investigated fluids, R152a is the most appropriate for waste heat sources, whereas Isopentane is more effective for the solar heat source with temperatures between $125^{\circ} \mathrm{C}$ and $275^{\circ} \mathrm{C}$.

Zhang et al. [3] have studied the subcritical ORC configuration with different heat exchanger types. In their study, the have investigated plate, shell-and-tube and finned-tube heat exchangers for the evaporator and condenser. The heat source is flue gas with a temperature of $120-200^{\circ} \mathrm{C}$ and a flow rate of $10 \mathrm{~kg} / \mathrm{s}$. They have considered the electricity production cost $(\mathrm{EPC})$ as the optimization objective and found that the ORC with finned tube bundles with circular fins for the evaporator and a shell-and-tube condenser is the most cost-effective configuration, with $E P C=0.055-0.070 \$ / \mathrm{kWh}$ for the investigated conditions.

$\mathrm{Xi}$ et al. 4. have economically investigated an ORC for four mixtures and five pure working fluids, for heat source temperatures of $100-180^{\circ} \mathrm{C}$. They have minimized the electricity production cost, using a Genetic Algorithm for the optimization. Their main conclusions are that the mixture working fluids are economically more efficient, mainly due to a lower evaporator capital cost.

Budisulistyo et al. 5] have proposed a lifetime design strategy which takes into account heat source degradation of the geothermal source. They have implemented an air-cooled subcritical ORC in Aspen and used SQL for the optimization. The authors have considered the geothermal source 
conditions in years 1, 7, 15 and 30 to design the ORC towards maximal net electrical power output. Initially, the geothermal source has a temperature of $131^{\circ} \mathrm{C}$ and a mass flow rate of $200 \mathrm{~kg} / \mathrm{s}$. For every ORC design, they have investigated the net present value and the energy return on investment over a lifetime of 30 years, taking into account changing brine and environmental conditions. They have concluded that the design in year 7 has the highest net present value $(6,894,615 \$)$.

35 We see that multiple economic optimization criteria are used in the literature. However, we prefer using the Net Present Value (NPV) concept since it gives a direct indication whether the project is profitable or not, taking into account all necessary variables. A proper choice of the economic parameter values (e.g. the electricity price - evolution over time -, discount rate and lifetime) is very important since unconsidered assumptions on the economic conditions might result in strong deviations between the real income and the estimated one. Whereas, in the literature, the focus is often on the influence of heat source conditions and environmental parameters, we focus on the assumptions in the economic calculations. In this paper, we investigate multiple scenarios for the economic situation and discuss the effect on the economic feasibility of a low-temperature geothermal power plant. In the literature, generally, the economic feasibility is evaluated for a fixed design of the ORC (a fixed physical ORC installation); in this work, however, we optimize the ORC design and operating conditions depending on the assumed economic situation. Hence the physical ORC implementation depends on the economic parameter values.

\section{Thermo-economic model}

In this section, the thermo-economic model is discussed. First, the considered ORC set-up is given and the brine and environmental conditions are defined. Second, a short motivation of the working fluid choice is given. Then, the detailed thermodynamic model equations (correlations for pressure drop and heat transfer) and cost functions are given. And finally the optimization problem is stated.

\subsection{Basic ORC set-up}

${ }_{55}$ We consider electrical power generation via a basic ORC. A schematic presentation is shown in Figure $1 \mathrm{a}$ and the thermodynamic states are indicated. The brine adds heat to the working fluid, 


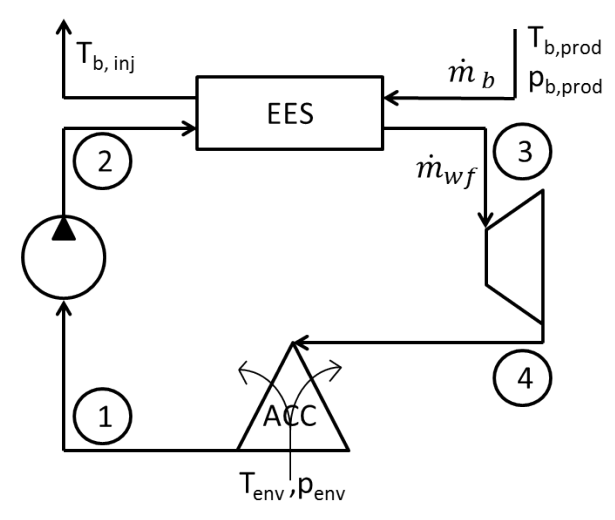

(a) Basic ORC set-up.

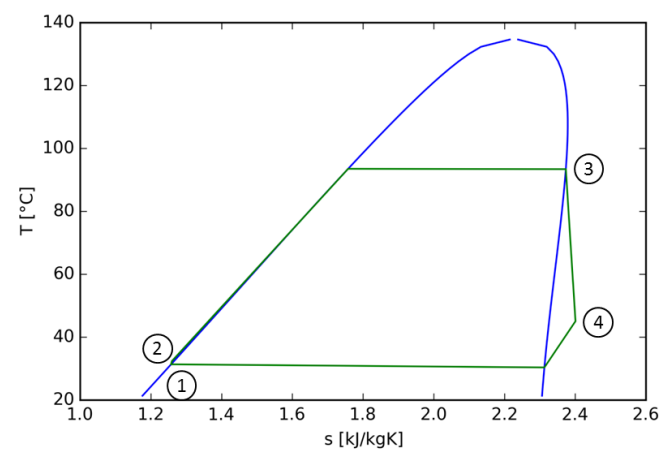

(b) Temperature-entropy diagram. Blue: bubble line and dew line of Isobutane, green: working fluid states.

Figure 1: Schematic presentation of the basic ORC with indication of the thermodynamic working fluid states.

which undergoes the energy conversion cycle. The working fluid is pressurized by the pump (state 1 $\rightarrow$ state 2 ), evaporated (state $2 \rightarrow$ state 3 ), expanded in the turbine (state $3 \rightarrow$ state 4 ) and thereby generating electricity via the connected generator, and condensed back to state 1 . Figure $1 \mathrm{~b}$ shows the temperature-entropy diagram with the bubble and dew lines for Isobutane and indication of the working fluid states.

For the economizer, evaporator and superheater (named EES on Figure 1a), we consider TEMA E shell\&tube-type heat exchangers [6] with one pass on both, the shell and the tube side. Due to the high brine pressure (which is needed to avoid salt sedimentation and to avoid condensable gasses to escape), shell\&tube heat exchangers are more appropriate than plate-type exchangers [7]. An air-cooled condenser (ACC on Figure 1a) is considered, since it is often implemented and no water has to be available. We opt for an A-framed ACC with flat tubes and corrugated fins because the pressure drop is smaller than for round tubes. The fans are located at the bottom side of the A-frame such that forced-draft cooling is imposed.

The parameter values for the brine conditions as well as the power of the well pumps, the well costs and costs associated with handling of the brine are based on the first estimates for the Balmatt geothermal site (Mol, Belgium), which is currently under construction $[8$. The brine is modeled 


\begin{tabular}{c|c|c|c|c|c} 
& $\mathrm{MW}[\mathrm{g} / \mathrm{mole}]$ & $T_{\text {crit }}\left[{ }^{\circ} \mathrm{C}\right]$ & $p_{\text {crit }}[\mathrm{MPa}]$ & ODP & GWP \\
\hline Isobutane (R600a) & 58.12 & 134.66 & 3.63 & 0 & 20
\end{tabular}

Table 1: Thermodynamic and environmental properties of Isobutane [10].

as pure water and the brine production temperature, pressure and flow rate are $T_{b, p r o d}=130^{\circ} \mathrm{C}$, $p_{b, p r o d}=40 \mathrm{bar}(\mathrm{a})$ and $\dot{m}_{b}=194 \mathrm{~kg} / \mathrm{s}$, respectively. The well pumps power and the well drilling costs are $\dot{W}_{\text {wells }}=600 \mathrm{~kW}$ and $I_{\text {wells }}=27.5 \mathrm{MEUR}$, respectively. The well drilling costs are high due to a low thermal gradient of only $30^{\circ} \mathrm{C} / \mathrm{km}$ 9]. Furthermore, the environmental temperature and pressure are $T_{e n v}=10.3^{\circ} \mathrm{C}$ and $p_{e n v}=1.016 \mathrm{bar}(\mathrm{a})$, respectively.

\subsection{Working fluid}

The working fluid Isobutane (R600a) is chosen due to its very low environmental impact [10] and a

so good ORC performance. Furthermore, hydrocarbons are relatively cheap and cost approximately $2.5 \$ / \mathrm{kg}$ (number for the year 2015) according to Macchi et al. [7]. The thermodynamic parameters as well as the Ozone Depletion Potential (ODP) and Global Warming Potential (GWP) of Isobutane are summarized in Table 1 .

\subsection{Thermodynamic model equations}

${ }_{85}$ The model equations are based on the work of Walraven et al. [11, 12, 13. We consider 1 pass $/ 1$ pass TEMA E shell\&tube heat exchangers. The split-ring floating-head tube bundle is assumed because it is the most appropriate for situation where thermal expansion is required and cleaning on the shell-side is not needed [6]. The brine flows through the tubes and the working fluid flow through the shell.

90 The geometrical design variables which are optimized are the shell inner diameter $D_{\text {shell }}$, the tube outer diameter $D_{\text {tube }}$, the pitch between the tubes $p_{t u b e}$, the baffle cut length $B_{c}$ and the baffle spacing $L_{b c}$. From previous work [11, we know that the $30^{\circ}$ tube bundle layout is the most appropriate for the economizer and superheater, whereas the $60^{\circ}$ layout shows better performance for the two-phase heat transfer in the evaporator. For the geometrical calculations, we follow the general procedure as proposed in the literature [6, 14, 15]. 
The heat transfer is modeled by the following set of equations:

$$
\begin{aligned}
& \dot{Q}=U A L M T D \\
& \frac{1}{U}=\frac{1}{h_{\text {tube }}}+\frac{\delta}{k}+\frac{1}{h_{\text {shell }}}
\end{aligned}
$$

with $L M T D$ the $\log$ mean temperature difference, $A$ the heat transfer surface area, and $U$ the total heat transfer coefficient. $\delta=2.5 \mathrm{~mm}$ is the wall thickness and $k=18 \mathrm{~W} / \mathrm{mK}$ the thermal conductivity of the wall. $h_{\text {tube }}$ and $h_{\text {shell }}$ are the convective heat transfer coefficients on the tube side and the shell side, respectively. The heat transfer coefficient on the tube side $h_{t u b e}$ is calculated according to the correlation of Petukhov and Popov [16]. The frictional coefficient for the tubes is calculated following the correlation of Bhatti and Shah [17. The shell side calculations are based on the Bell-Delaware method [6, 14, 18. The convective heat transfer coefficient $h_{\text {shell }}$ is calculated from the ideal heat transfer coefficient for cross-flow over a tube bundle, and corrected for the baffle configuration and the baffle leakages. The one-phase heat transfer and pressure drop are calculated following [6], the two-phase (boiling) in the evaporator is modeled following [14. For more information and the detailed equations, the reader is referred to [11.

The tubes of the A-frame ACC make an angle of $60^{\circ}$ with the horizontal. The rectangular tubes have dimensions of $19 \mathrm{~mm} \times 200 \mathrm{~mm}$ and the fin thickness is $0.25 \mathrm{~mm}$. The geometrical design parameters which are optimized are the length of the tubes $L_{A C C}$, the fin height $H_{f i n}$ and the fin spacing $S_{\text {fin }}$. The air-side calculations are based on the correlation of Yang et al. [19]. For the working fluid on the tube side, the correlation of Petukhov and Popov [16] and the Gnielinski correlation 20] are used for the frictional and heat transfer coefficient calculations of the desuperheater. For the two-phase flow in the condenser, the CISE correlation [21, the correlation of Shah [22] and the Chisholm correlation [23] are used for the calculations of the void fraction, the heat transfer and the pressure drop coefficient, respectively. For more information and the detailed equations, the reader is referred to [12].

Furthermore, we assume constant isentropic pump $\left(\eta_{p}=80 \%\right)$ and turbine $\left(\eta_{t}=85 \%\right)$ efficiencies, fixed motor $\left(\eta_{m}=98 \%\right)$ and generator $\left(\eta_{g}=98 \%\right)$ efficiencies as well as a fixed efficiency (mechanical and electrical) of the fan $\left(\eta_{f}=60 \%\right)$. 


\begin{tabular}{c|c|c|c|c} 
& capacity measure & size range & cost correlation $[\$]$ & ref \\
\hline shell\&tube HEx & $\mathrm{A}\left[\mathrm{m}^{2}\right]$ & $80-4000 \mathrm{~m}^{2}$ & $3.2810^{4}(A / 80)^{0.68}$ & {$[24]$} \\
centr. pump (incl. motor) & $\dot{W}[W]$ & $4-700 k W$ & $9.8410^{3}(\dot{W} / 4000)^{0.55}$ & {$[24]$} \\
turbine & $\dot{W}[W]$ & $0.1-20 M W$ & $-19000+820(\dot{W} / 1000)^{0.8}$ & {$[26]$} \\
ACC excl. fan & $\mathrm{A}\left[\mathrm{m}^{2}\right]$ & $200-2000 m^{2}$ & $1.5610^{5}(A / 200)^{0.89}$ & {$[24]$} \\
ACC fan (incl. motor) & $\dot{W}[W]$ & $50-200 k W$ & $1.2310^{4}(\dot{W} / 50000)^{0.76}$ & {$[24$}
\end{tabular}

Table 2: Bare equipment cost correlations. Table is adapted from [12.

The cost functions of the bare equipment costs CBE are summarized in Table 2, Due to the high temperature $\left(>100^{\circ} \mathrm{C}\right)$, the high pressure $(>7$ bar $)$ and the need for stainless steel, the correction factors $f_{T}=1.6, f_{p}=1.5, f_{M}=1.6$ are respectively taken into account [24]. Additionally, an installation cost factor of $f_{I}=0.6$ [25] is taken into account. The final equipment cost $\mathrm{C}$ thus becomes:

$$
C=C_{B E}\left(f_{T} f_{P} f_{M}+f_{I}\right)
$$

Finally, the costs are translated to 2016-based values by means of the chemical engineering index and are converted to euro.

\subsection{Optimization problem}

The models are implemented in Python [27] using the CasADi 28] optimization framework together with the IpOpt 29] non-linear solver. Fluid properties are called from the REFPROP 8.0 database 30.

The objective is to maximize the Net Present Value (NPV), which is defined as:

$$
N P V=-I_{\text {wells }}-I_{O R C}+\sum_{i=1}^{L T} \frac{\dot{W}_{n e t} p_{e l}\left(1+d_{e l}\right)^{i} \frac{8760}{10^{6}} N-0.025 I_{O R C}}{(1+d r)^{i}} \quad[M E U R]
$$

Herein are $I_{w e l l s}$ the well drilling costs and $I_{O R C}$ the total ORC investment costs, $p_{e l}$ the yearly averaged wholesale electricity price, $d_{e l}$ the relative yearly electricity price increase, $N$ the availability factor, $d r$ the discount rate, $L T$ the lifetime and $\dot{W}_{\text {net }}$ the net electrical power. According to 


\begin{tabular}{|c|c|c|c|c|c|}
\hline \multicolumn{3}{|c|}{ variables of the optimization process } & \multicolumn{3}{|c|}{ additional constraints } \\
\hline variable & lower bound & upper bound & constraint & lower bound & upper bound \\
\hline$T_{\text {cond }}\left[{ }^{\circ} \mathrm{C}\right]$ & $T_{e n v}$ & $\min \left(T_{b, \text { prod }}, T_{\text {upper }}\right)$ & $D_{\text {tube }} / D_{\text {shell }}[-]$ & 0 & 0.1 \\
\hline$T_{\text {evap }}\left[{ }^{\circ} \mathrm{C}\right]$ & $T_{e n v}$ & $\min \left(T_{b, \text { prod }}, T_{\text {upper }}\right)$ & $T_{t}-T_{\text {evap }}\left[{ }^{\circ} \mathrm{C}\right]$ & 0.01 & $T_{\text {upper }}-T_{\text {env }}$ \\
\hline$T_{t}\left[{ }^{\circ} \mathrm{C}\right]$ & $T_{e n v}+10^{\circ} \mathrm{C}$ & $\min \left(T_{\text {crit }}, T_{\text {upper }}\right)$ & $T_{\text {evap }}-T_{\text {cond }}\left[{ }^{\circ} \mathrm{C}\right]$ & 10 & $2\left(T_{\text {upper }}-T_{\text {env }}\right)$ \\
\hline$\dot{m}_{w f} / \dot{m}_{b}[-]$ & 0.01 & 5 & $T_{b, i n j}\left[{ }^{\circ} C\right]$ & 25 & $T_{b, p r o d}$ \\
\hline$D_{\text {shell }}[\mathrm{m}]$ & 0.3 & 2 & $\Delta T_{\text {pinch }}\left[{ }^{\circ} \mathrm{C}\right]$ & 1 & 100 \\
\hline$D_{\text {tube }}[\mathrm{mm}]$ & 12.7 & 50.8 & $L_{A C C}[\mathrm{~m}]$ & 0 & 20 \\
\hline$p_{\text {tube }}[-]$ & 1.25 & 1.5 & & & \\
\hline$B_{c}[-]$ & 0.25 & 0.45 & & & \\
\hline$L_{b c}[\mathrm{~m}]$ & 0.05 & 2 & & & \\
\hline$S_{f i n}[\mathrm{~mm}]$ & 1.14 & 3.04 & & & \\
\hline$H_{\text {fin }}[\mathrm{mm}]$ & 14.25 & 23.75 & & & \\
\hline$v_{a i r}[\mathrm{~m} / \mathrm{s}]$ & 1.5 & 20 & & & \\
\hline$n_{\text {tube }}[-]$ & 500 & 10000 & & & \\
\hline
\end{tabular}

Table 3: Lower and upper bounds of the variables of the optimization process and additional constraints.

In our optimization, the operating conditions (condenser $T_{\text {cond }}$, evaporator $T_{\text {evap }}$ and turbine $T_{t}$ temperatures, the working fluid mass flow rate $\dot{m}_{w f}$ and the air flow rate $v_{a i r}$ ) are optimized together with the design of the heat exchangers and the ACC design. The variables and their upper and lower bounds are given on the left hand side of Table 3 . The heat exchanger design limits are derived from [11, 32, 33] whereas the limits on the ACC design follow from [12, 19].

Additional constraints are given on the right hand side of Table $3 . \Delta T_{\text {pinch }}$ is the minimum temperature difference over the heat exchangers, $L_{A C C}$ is the length of a leg of the ACC A-frame. We did not impose a limit on the brine injection temperature $T_{b, i n j}$.

\section{Optimization results}

The goal of this work is to study the feasibility of a geothermal project at a specified physical location, for multiple economic scenarios. As such, the brine production state and brine flow rate, 


\begin{tabular}{c|c|c|c|c|c|c} 
& 1 & 2 & high & low & 1-LT25 & 1-LT20 \\
\hline$p_{\text {el }}$ [EUR/MWh] & $\mathbf{5 0}$ & $\mathbf{3 6}$ & $\mathbf{8 0}$ & $\mathbf{2 5}$ & 50 & 50 \\
$d_{\text {el }}$ [\%/year] & $\mathbf{5}$ & $\mathbf{1 . 5}$ & $\mathbf{5}$ & $\mathbf{1 . 5}$ & 5 & 5 \\
$d r[\%]$ & $\mathbf{4}$ & $\mathbf{0 . 3}$ & $\mathbf{0 . 3}$ & $\mathbf{5}$ & 4 & 4 \\
$L T$ [year] & 30 & 30 & 30 & 30 & $\mathbf{2 5}$ & $\mathbf{2 0}$ \\
\hline$N$ [\%] & 98 & 98 & 98 & 98 & 98 & 98 \\
$I_{\text {wells }}[\mathrm{MEUR}]$ & 27.5 & 27.5 & 27.5 & 27.5 & 27.5 & 27.5
\end{tabular}

Table 4: Economic parameter values for the different economic scenarios: varying external parameters (electricity price - evolution over time-, discount rate and lifetime). Values based on 37 38, 39.

as well as the environmental conditions are kept constant.

\subsection{Definition of the different scenarios}

For all scenarios, the Chemical Engineering index $\mathrm{CE}=557$ (March 2016) 34] and the dollar-to-

euro conversion factor $f_{\$-E U R}=1.11 \$ /$ EUR (March 2016) [35] are kept constant. Furthermore, we distinguish internal and external economic parameters. On the one hand, the wholesale electricity price, the electricity price variation over time, the discount rate and the lifetime are the external economic parameters. On the other hand, the well drilling and brine handling costs and the availability factor are the internal parameters, which are directly related to the maturity of the drilling and production technology/geothermal gradient/reservoir management and the need for maintenance works (the robustness of the ORC installation).

The economic parameter values for the different scenarios are given in Table 4 (external parameters) and Table 5 (internal parameters). Scenarios 1 and 2 are based on the economic conditions in Belgium in 2013 and 2016, respectively. The high and low scenarios with a high and a low electricity price are expected to have a high and a low NPV, respectively. The scenarios 1-LT25 and 1-LT20 have the same economic conditions as scenario 1 ; however the lifetime is 25 and 20 years instead of 30 years. Scenarios $1-N 80,1-N 85,1-N 90,1-N 95$ and $1-N 100$ represent a $80,85,90,95$ and $100 \%$ availability factor [36] and in the scenarios $1-I 15$ and $1-I 0$, the costs for drilling and production of the brine are studied. 


\begin{tabular}{c|c|c|c|c|c|c|c|c} 
& 1 & $1-N 80$ & $1-N 85$ & $1-N 90$ & $1-N 95$ & $1-N 100$ & $1-I 15$ & $1-I 0$ \\
\hline$p_{e l}$ [EUR/MWh] & 50 & 50 & 50 & 50 & 50 & 50 & 50 & 50 \\
$d_{\text {el }}[\% /$ year] & 5 & 5 & 5 & 5 & 5 & 5 & 5 & 5 \\
$d r[\%]$ & 4 & 4 & 4 & 4 & 4 & 4 & 4 & 4 \\
$L T$ [year] & 30 & 30 & 30 & 30 & 30 & 30 & 30 & 30 \\
\hline$N$ [\%] & 98 & $\mathbf{8 0}$ & $\mathbf{8 5}$ & $\mathbf{9 0}$ & $\mathbf{9 5}$ & $\mathbf{1 0 0}$ & 98 & 98 \\
$I_{\text {wells }}[\mathrm{MEUR}]$ & 27.5 & 27.5 & 27.5 & 27.5 & 27.5 & 27.5 & $\mathbf{1 5}$ & $\mathbf{0}$
\end{tabular}

Table 5: Economic parameter values for the different economic scenarios: varying internal parameters (availability factor and well drilling costs).

\subsection{Feasibility under different external economic conditions}

First, we investigate the effect of the average wholesale electricity price (evolution over time) and the discount rate on the economic feasibility of the power plant. Figure 2 shows the results on the $\mathrm{NPV}$, the ORC cost, the net electrical power output $\dot{W}_{n e t}$, the exergetic plant efficiency $\eta_{e x}$ and the energetic cycle efficiency $\eta_{e n}$, corresponding to the economic parameter values of Table $4 . \eta_{e x}$ and $\eta_{e n}$ are defined as: $\eta_{e x}=\dot{W}_{n e t} / \dot{E} x_{b}$ and $\eta_{e n}=\dot{W}_{n e t} / \dot{Q}_{O R C}$, with $\dot{E} x_{b}$ the brine flow exergy referred to the environmental conditions and $\dot{Q}_{O R C}$ the heat addition to the ORC.

When comparing scenarios 1 and 2 , we see that scenario 1 is a profitable case whereas scenario 2 is not. Besides, the high electricity price-evolution over time-and the low discount rate in scenario high result in a very high NPV whereas the low electricity price and the high discount rate of scenario low lead to a low NPV. Furthermore, from Figure 2, we can see that the ORC equipment cost, the net electrical power output, the exergetic plant efficiency and energetic cycle efficiency follow the same trend as the NPV. This can be explained as follows. In scenarios with a high electricity price, a better performing hence more expensive ORC can be afforded; the net electrical power output is higher, the efficiencies are higher but the individual component costs (ACC is the most expensive) are also higher. Because the ORC cost is much smaller than the well drilling costs, the incomes from selling more electricity more than offset the extra ORC component costs. As a result, also the NPV is higher. Remark also the importance of a good cooling system. Lowering the cooling temperature with a few degrees requires huge additional investments in the ACC but returns a higher electrical power output (scenario high versus scenario low). 

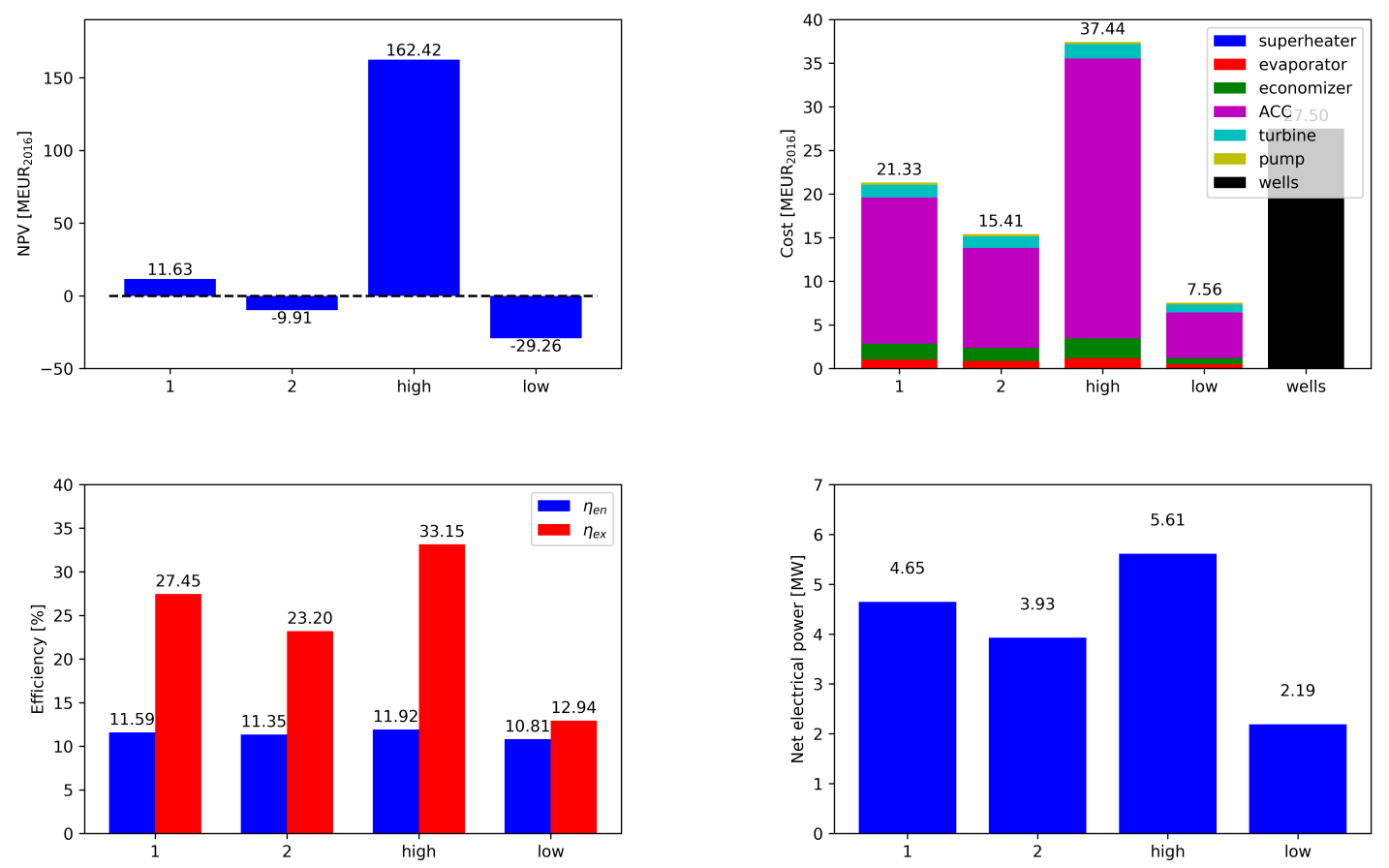

Figure 2: Net present value (NPV), cost-breakdown, efficiencies and net electrical power output for the 1, 2, high and low scenarios (defined in Table 4. The well drilling costs is the same for all four scenarios shown.

On the left-hand side of Figure 3, we show the operating temperatures and the brine injection temperature. For scenarios with a high NPV, the brine injection temperature is lower and more heat is transferred to the ORC cycle. This requires larger heat exchangers and is thus more expensive. The turbine inlet temperature and the evaporator temperatures follow the same trend as the brine injection temperature. Note that the turbine inlet temperature equals the evaporator temperature (up to the imposed constraint of $0.01^{\circ} \mathrm{C}$ from Table 3 since superheating is not favorable in case of a dry working fluid like Isobutane [40, 41]. The condenser temperature also follows the same trend. A lower condenser temperature requires more investments but results in a higher power output.

Finally, on the right-hand side of Figure 3 we show the LCOE (Levelized Cost of Electricity) values which correspond to the NPV-optimized scenarios. The LCOE is the fictitious average price of electricity during the entire lifetime which would result in a break-even for the investor/operator 

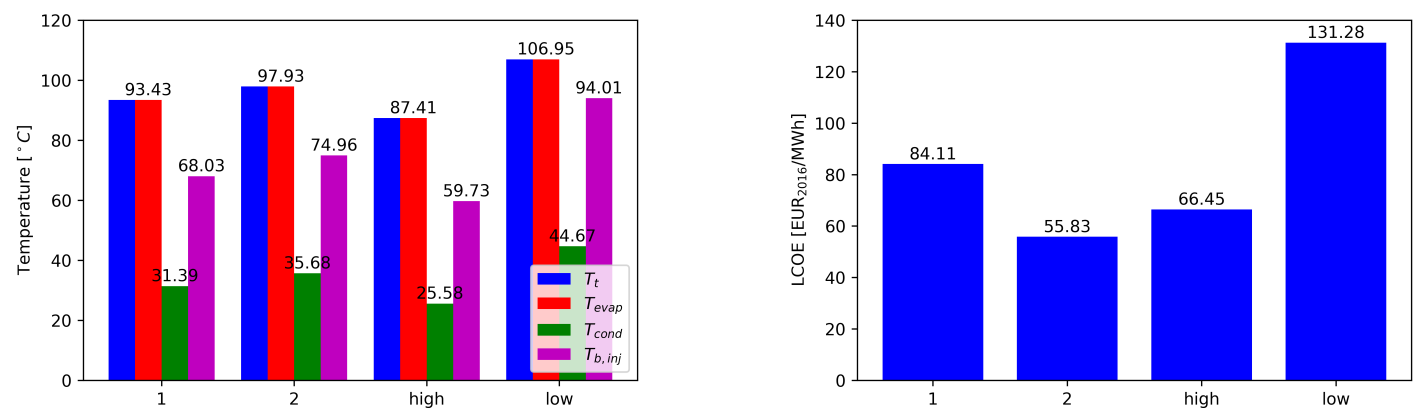

Figure 3: Left-hand side: Operating temperatures (turbine inlet temperature $T_{t}$, evaporator temperature $t_{\text {evap }}$ and condenser temperature $T_{\text {cond }}$ ) and brine injection temperature $T_{b, i n j}$ for the 1,2 , high and low scenarios (defined in Table 4. Right-hand side: Levelized Cost of Electricity (LCOE) for the 1, 2, high and low scenarios (defined in Table 4 .

of the plant. The trend of the LCOE is different from the trend of the NPV. This follows directly from the LCOE definition:

$$
L C O E=\frac{I_{\text {wells }}+I_{O R C}+\sum_{i=1}^{L T} \frac{0.025 I_{O R C}}{(1+d r)^{i}}}{\sum_{i=1}^{L T} \frac{\dot{W}_{n e t} N \frac{8760}{10^{6}}}{(1+d r)^{i}}} \quad[E U R / M W h]
$$

Based on the very high NPV-value of the high scenario, we would expect this scenario to have the lowest LCOE. However, this is not the case: the net electrical power output is higher but also the investment costs are very high. This still results in a relatively high value of the LCOE. A more detailed elaboration on the NPV and the LCOE as optimization objectives is given in Section 3.4

We conclude that the high scenario has the highest NPV, followed by scenario 1, 2 and low. The payback time of scenario high and 1 are 14 and 25 years, respectively. The net electrical power output and the ORC cost are the highest for the high scenario, followed by scenarios 1, 2 and low. However, the LCOE shows a different trend. The high scenario does not result in the lowest LCOE due to the very high investment costs.

Last, consider the effect of the assumed lifetime on scenario 1. The results, corresponding to the input values of Table 4, are summarized in Table 6. For a lifetime of 30 years, the project is profitable with NPV $=11.63 \mathrm{MEUR}$. However, for a smaller expected lifetime of 25 or 20 years, 


\begin{tabular}{c|c|c|c} 
& 1 & $1-$ LT25 & $1-$ LT20 \\
\hline$N P V\left[\mathrm{MEUR}_{2016}\right]$ & 11.63 & -0.26 & -10.74 \\
$\dot{W}_{\text {net }}[\mathrm{MW}]$ & 4.65 & 4.41 & 4.08 \\
$T_{b, \text { inj }}\left[{ }^{\circ} \mathrm{C}\right]$ & 68.03 & 70.29 & 73.51 \\
$\eta_{\text {ex }}[\%]$ & 27.45 & 26.10 & 24.06 \\
$\eta_{\text {en }}[\%]$ & 11.59 & 11.52 & 11.40
\end{tabular}

Table 6: Influence of the lifetime on the plant feasibility for scenario 1 (defined in Table 4 .

the project is not profitable. For a lower lifetime, fewer expenses can be afforded and less effort is made to extract heat from the brine. As a result, the brine injection temperature is higher. Also less effort is done on the cooling side and a cheaper ACC is installed. Both effects have a negative impact on the net electrical power output and the efficiencies are lower.

\subsection{Feasibility under different internal economic conditions}

In this section, we investigate the effect of the internal economic conditions-the availability factor and the well drilling costs - on scenario 1, corresponding to the input parameters of Table 5 .

First, we discuss the results for six values of the availability factor: $\mathrm{N}=80 \%, \mathrm{~N}=85 \%, \mathrm{~N}=90 \%$, $\mathrm{N}=95 \%, \mathrm{~N}=98 \%$ and $\mathrm{N}=100 \%$. The assumption of $100 \%$ availability means that the ORC would run during the entire year which is unrealistic but it is taken as a reference for comparison. Table 7 summarizes the results. We see that the NPV increases with the availability factor. The ORC operates more hours during the year hence the income is higher. This goes furthermore hand in hand with a more expensive and more efficient ORC, hence a lower brine injection temperature, higher energetic cycle efficiency and higher exergetic plant efficiency. The higher ORC cost is mainly due to the higher cooling system costs. So, as a summary, the higher the availability factor the better the economic feasibility, as we could expect. Considering the ORC installation only, the availability factor might be higher than $98 \%$. However, accounting for issues related to the brine composition (such as fouling of the brine heat exchangers) and the well productivity, the availability factor may go down to only $80 \%$. This has a big impact on the NPV. For availability factors higher than $95 \%$, the NPV value is higher than 9.5MEUR. However, if the availability factor would be only 


\begin{tabular}{c|c|c|c|c|c|c} 
& $1-N 100$ & 1 & $1-N 95$ & $1-N 90$ & $1-N 85$ & $1-N 80$ \\
\hline$N P V\left[\mathrm{MEUR}_{2016}\right]$ & 13.05 & 11.63 & 9.51 & 6.01 & 2.57 & -0.81 \\
$I_{O R C}\left[\mathrm{MEUR}_{2016}\right]$ & 21.60 & 21.33 & 20.92 & 20.21 & 19.48 & 18.73 \\
$\dot{W}_{\text {net }}[\mathrm{MW}]$ & 4.67 & 4.65 & 4.61 & 4.54 & 4.46 & 4.37 \\
$T_{b, \text { inj }}\left[{ }^{\circ} \mathrm{C}\right]$ & 67.79 & 68.03 & 68.40 & 69.07 & 69.81 & 70.63 \\
$\eta_{\text {ex }}[\%]$ & 27.60 & 27.45 & 27.21 & 26.79 & 26.33 & 25.83 \\
$\eta_{\text {en }}[\%]$ & 11.60 & 11.59 & 11.58 & 11.56 & 11.53 & 11.51
\end{tabular}

Table 7: Influence of the availability factor on the scenario 1 feasibility (input values are defined in Table 5 .

$80 \%$, the project becomes economically unfeasible for the considered brine and economic conditions $(N P V<0)$.

Second, we discuss the effect of the well drilling costs on the optimal plant layout for scenario 1. We find that the operating conditions, the optimal design and hence the component costs are independent of the well drilling costs and equal to the results of scenario 1. Referring to Eq. (4), which gives the definition of the NPV, we see that $I_{\text {wells }}$ has a fixed value and is independent of the optimization variables. Therefore, the well costs have no influence on the optimized variables (the values of the variables which were given in Table 3). However, the well costs do influence the value of the NPV itself. NPV $=11.63 \mathrm{MEUR}, \mathrm{NPV}=24.13 \mathrm{MEUR}$ and $\mathrm{NPV}=39.13 \mathrm{MEUR}$ for scenarios 1, 1-I15 and 1-I0, respectively. The difference in the NPV values is purely caused by the difference in the well costs. The payback time decreases from 25 years for $I_{\text {wells }}=27.5 \mathrm{MEUR}$ to 12 years in case of no well costs $\left(I_{\text {wells }}=0\right.$ MEUR $)$.

\subsection{Discussion: NPV as optimization objective}

From the last section, we know that the well drilling and brine handling costs do not influence the optimal design and operating conditions of the ORC. Also the ORC cost is the same for different values of $I_{\text {wells }}$. However, we expect that for higher costs for drilling and production of the brine, also higher investments in the ORC equipment might be justified in order to get a higher income from the electricity production.

To take into account this phenomenon, we optimize scenarios 1, 1-I15 and 1-I0 yet using the LCOE (defined in Eq. (5)) as the optimization objective to be minimized instead of the NPV 

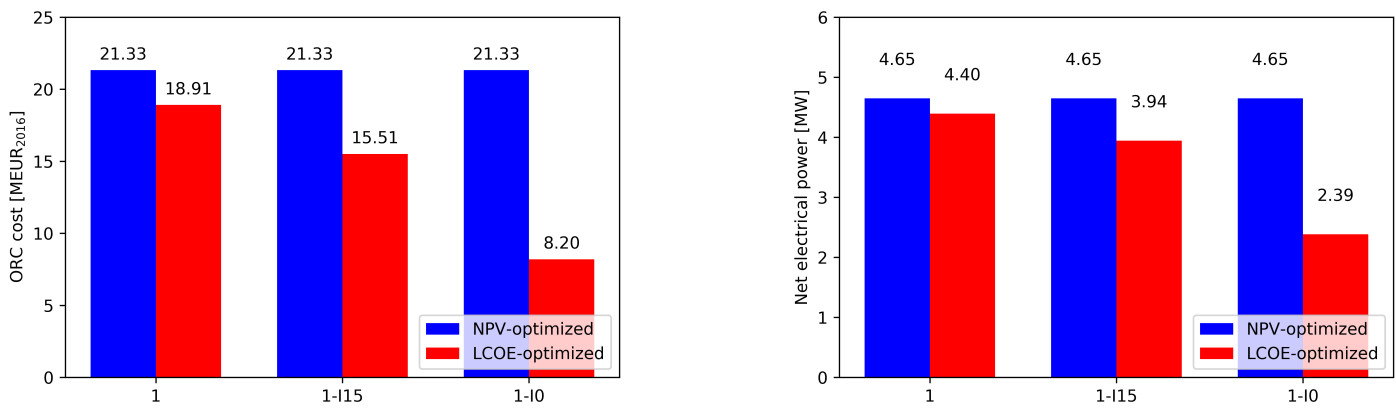

Figure 4: Comparison of the ORC cost and the net electrical power output of the NPV-optimized (blue) and LCOEoptimized (red) results for scenarios 1, 1-I15 and 1-I0 (defined in Table 5).

\begin{tabular}{c|c|c|c|c|c|c} 
& \multicolumn{3}{|c|}{ NPV optimization } & \multicolumn{3}{c}{ LCOE optimization } \\
& 1 & $1-I 15$ & $1-I 0$ & 1 & $1-I 15$ & $1-I 0$ \\
\hline$N P V\left[\mathrm{MEUR}_{2016}\right]$ & 11.63 & 24.13 & 39.13 & 11.29 & 21.90 & 24.00 \\
$L C O E\left[\mathrm{EUR}_{2016} / \mathrm{MWh}\right]$ & 84.11 & 66.00 & 44.27 & 83.66 & 63.56 & 33.18
\end{tabular}

Table 8: Comparison of the NPV and the LCOE values of the NPV-optimized and LCOE-optimized results for scenarios 1, 1-I15 and 1-IO (defined in Table 5 .

(defined in Eq. (4)) which was to be maximized. The economic parameter values were given in Table 5 however, for the LCOE optimization we do not impose any value for the electricity price (evolution over time). The results are summarized in Figure 4 and Table 8.

As been said before, for the NPV optimization, the difference between the values of the NPV is purely caused by the well costs (left-hand side of Table 8). The total ORC cost is the same for every scenario (left-hand side of Figure 4). When we compare the LCOE-optimized results with the NPV-optimized results, we see that the optimal design and operating conditions are different, hence the ORC costs are also different (left-hand side of Figure 4). The net power generation in the LCOE-optimized case is smaller than for the NPV-optimized results (right-hand side of Figure (4), which is mainly the result of a higher brine injection temperature. From Table 8, we see that the results of the NPV-optimization and the LCOE-optimization are in good agreement in case of high well drilling costs (scenario 1). However, for low costs for drilling and production of the brine, the results are significantly different. 
Note that, in our optimization, we optimize the operating conditions and the design of the ORC towards the best value of the objective function. Depending on the choice of the objective function, the optimal design-and hence the physical implementation of the ORC-is different.

Furthermore, considering the LCOE-optimized results only, the optimal values of the variables are different for different scenarios (different well costs), which is in contrast to the NPV-optimized values. For higher well drilling costs, the ORC is more expensive (left-hand side of Figure 4 ) and has a higher net electrical power output (right-hand side of Figure 4 ).

Depending on the involved party, either the NPV or the LCOE might be the most interesting performance indicator. The three main differences are:

1. The NPV gives a direct indication whether the project is profitable or loss-making, whereas the LCOE does not.

2. The NPV-calculation requires assumptions for a lot of external economic parameters which are very hard to predict. No assumptions regarding electricity pricing are needed in case of the LCOE-calculation.

3. The well costs are not taken into account in case of the NPV-optimization and the same ORC would be built independent of the well costs. The LCOE is a better way of comparing the cost of the wells and the extra cost of a better-performing ORC, with the additional electrical power output.

\section{Conclusions}

In this work, we have studied the feasibility of a binary geothermal power plant for multiple economic scenarios. In our thermo-economic optimization, we maximize the NPV and the design of the heat exchangers and the ACC and the operating conditions are optimized together.

Regarding the external economic parameters, we conclude that the highest NPV is reached for a high value of the electricity price, a high price evolution over time and a low discount rate. For these economic conditions, a better performing ORC can be justified: the net electrical power output is higher, the efficiencies are higher but also the component costs are higher (the ACC is responsible for a large share of the ORC costs, up to $86 \%$ for the investigated scenarios). We find that the same 
geothermal project might be profitable for scenario 1 with $N P V=11.63 M E U R_{2016}$ or loss-making for scenario 2 with $N P V=-9.91 M E U R_{2016}$, only depending on the economic situation. In case of a lower lifetime, fewer expenses can be afforded and a cheaper ORC is installed which results in a lower NPV of the project. The NPV changes from 11.63MEU $R_{2016}$ for a lifetime of 30 years to the loss-making value of $-10.74 M E U R_{2016}$ for a lifetime of only 20 years.

Furthermore, the internal economic parameters were studied. For a higher availability factor, more electricity can be sold for nearly the same ORC cost and the NPV is higher. The availability factor might have a big impact on the plant feasibility. Whereas $N P V=11.63 M E U R_{2016}$ for a $98 \%$ plant availability, the project might become unfeasible $\left(N P V=-0.81 M E U R_{2016}\right)$ for an $80 \%$ plant availability. The well drilling and brine handling costs do not influence the NPV-optimized results since they do not depend on the variables of the optimization procedure. The value of the NPV, however, does directly depend on the well drilling and brine handling costs. For well drilling and brine handling costs which are x MEUR higher, the NPV decreases with x MEUR.

Besides this last finding, we also found that the project with the highest NPV does not correspond with the project with the lowest LCOE value. The optimal design-and hence the physical implementation of the ORC-depends on the assumptions of the economic parameters on the one hand, but also on the choice of the optimization objective (maximization of the NPV or minimization of the LCOE) on the other hand. Whereas the NPV gives an indication whether the project is profitable or loss-making, the LCOE accounts for the well costs and does not need assumptions regarding the electricity pricing over time. Depending on the involved party, either the NPV or the LCOE might be the most interesting performance indicator.

\section{Acknowledgments}

This project receives the support of the European Union, the European Regional Development

Fund ERDF, Flanders Innovation \& Entrepreneurship and the Province of Limburg.

\section{Nomenclature}

Symbols and abbreviations 


\begin{tabular}{|c|c|}
\hline symbol & description \\
\hline$\$$ & US dollar \\
\hline$A\left[m^{2}\right]$ & heat transfer surface area \\
\hline$A C C$ & Air-Cooled Condenser \\
\hline$B_{c}[-]$ & baffle cut length \\
\hline$C[\mathrm{EUR}]$ & capital cost \\
\hline$D[\mathrm{~m}]$ & diameter \\
\hline$d_{e l}[\% /$ year $]$ & electricity price increase \\
\hline$d r[\%]$ & discount rate \\
\hline EES & economizer, evaporator and superheater \\
\hline$\dot{E x}[\mathrm{MW}]$ & flow exergy \\
\hline$f$ & correction factor \\
\hline$G W P$ & Global Warming Potential \\
\hline$H[\mathrm{~mm}]$ & height \\
\hline$h\left[\mathrm{~W} / m^{2} \mathrm{~K}\right]$ & convective heat transfer coefficient \\
\hline$I$ [MEUR $]$ & investment cost \\
\hline$k[\mathrm{~W} / \mathrm{mK}]$ & conductive heat transfer coefficient \\
\hline$L[\mathrm{~m}]$ & length \\
\hline$L_{b c}[\mathrm{~m}]$ & baffle spacing \\
\hline$L C O E[\mathrm{EUR} / \mathrm{MWh}]$ & Levelized Cost Of Electricity \\
\hline $\operatorname{LMTD}\left[{ }^{\circ} \mathrm{C}\right]$ & Log Mean Temperature Difference \\
\hline$L T$ [year] & LifeTime \\
\hline$\dot{m}[\mathrm{~kg} / \mathrm{s}]$ & mass flow rate \\
\hline$M W[\mathrm{~g} / \mathrm{mole}]$ & molecular weight \\
\hline$N[\%]$ & availability factor \\
\hline$n_{\text {tube }}[-]$ & number of tubes ACC \\
\hline$N P V[\mathrm{MEUR}]$ & Net Present Value \\
\hline$O D P$ & Ozone Depletion Potential \\
\hline$O R C$ & Organic Rankine Cycle \\
\hline$p$ [bar $]$ & pressure \\
\hline
\end{tabular}




\begin{tabular}{cc}
$p_{e l}[\mathrm{EUR} / \mathrm{MWh}]$ & electricity price \\
$p_{\text {tube }}[-]$ & pitch of tube bundle \\
$\dot{Q}[\mathrm{MW}]$ & thermal power \\
$S[\mathrm{~mm}]$ & spacing \\
$T\left[{ }^{\circ} \mathrm{C}\right]$ & temperature \\
$U\left[\mathrm{~W} / \mathrm{m}^{2} \mathrm{~K}\right]$ & overall heat transfer coefficient \\
$v[\mathrm{~m} / \mathrm{s}]$ & velocity \\
$\dot{W}[\mathrm{MW}]$ & electrical power \\
$\delta[\mathrm{m}]$ & tube thickness \\
$\eta[\%]$ & efficiency \\
\hline
\end{tabular}

Subscripts \& superscripts

\begin{tabular}{cc}
\hline symbol & description \\
\hline 1 & wf state at pump inlet \\
2 & wf state at pump outlet \\
3 & wf state at turbine inlet \\
4 & wf state at turbine outlet \\
air & air \\
$b$ & brine/geothermal water \\
BE & bare equipment \\
$C E$ & Chemical Engineering index \\
cond & condenser \\
crit & critical point \\
en & energetic \\
env & environment \\
evap & evaporator \\
ex & exergetic \\
$f$ & fan of ACC
\end{tabular}




\begin{tabular}{cc} 
fin & fin of ACC \\
$g$ & generator \\
$I$ & installation \\
inj & injection state \\
$M$ & material \\
$m$ & motor \\
net & net \\
$p$ & pump \\
pinch & pinch point \\
prod & production state \\
shell & shell of heat exchanger \\
$t$ & turbine \\
tube & tube of heat exchanger \\
wells & wells \\
wf & working fluid \\
\hline
\end{tabular}

\section{References}

[1] M. Imran, M. Usman, B.-S. Park, Y. Yang, Comparative assessment of Organic Rankine Cycle integration for low temperature geothermal heat source applications, Energy 102 (2016) 473-490.

[2] P. Garg, M. S. Orosz, P. Kumar, Thermo-economic evaluation of ORCs for various working fluids, Applied Thermal Engineering 109 (2016) 841-853.

[3] C. Zhang, C. Liu, S. Wang, X. Xu, Q. Li, Thermo-economic comparison of subcritical organic Rankine cycle based on different heat exchanger configurations, Energy 123 (2017) 728-741.

[4] H. Xi, M.-J. Li, Y.-L. He, Y.-W. Zhang, Economical evaluation and optimization of organic Rankine cycle with mixture working fluids using R245fa as flame retardant, Applied Thermal Engineering 113 (2017) 1056-1070. 
[5] D. Budisulistyo, C. S. Wong, S. Krumdieck, Lifetime design strategy for binary geothermal plants considering degradation of geothermal resource productivity, Energy Conversion and Management 132 (2017) 1-13.

[6] R. Shah, D. Sekulic, Fundamentals of Heat Exchanger Design, John Wiley and Sons, Inc., 2003.

[7] E. Macchi, M. Astolfi, Organic Rankine Cycle (ORC) Power Systems - Technologies and Applications, Elsevier, 2017.

[8] S. Bos, B. Laenen, Development of the first deep geothermal doublet in the Campine Basin of Belgium, European Geologist 43 (2017) 16-20.

[ [9] VITO, IOK, Voka, Diepe Geothermie, 2012. URL: http://www.diepegeothermie.be/nl/ aardwarmte-voor-pros/wat-is-diepe-geothermie/

[10] J. Calm, G. Hourahan, Physical, Safety and Environmental Data for Current and Alternative Refrigerants, in: International Congress of Refrigeration, Prague, Czech Republic, 2011. URL: http://www.hourahan.com/wp/wp-content/uploads/2010/08/ 2011-Physical-Safety-and-Environmental-Data2.pdf.

[11] D. Walraven, B. Laenen, W. D'haeseleer, Optimum configuration of shell-and-tube heat exchangers for the use in low-temperature organic Rankine cycles, Energy Conversion and Management 83 (2014) 177-187.

[12] D. Walraven, B. Laenen, W. D'haeseleer, Economic system optimization of air-cooled organic Rankine cycles powered by low-temperature geothermal heat sources, Energy 80 (2015) 104113.

[13] D. Walraven, B. Laenen, W. D'haeseleer, Minimizing the levelized cost of electricity production from low-temperature geothermal heat sources with ORCs: Water or air cooled?, Applied Energy 142 (2015) 144-153.

[14] G. Hewitt, Hemisphere Handbook of Heat Exchanger Design, Hemisphere Publishing Corporation, New York, 1990. 
[15] R. Mukherjee, Effectively design shell-and-tube heat exchangers, Chemical Engineering Progress 94 (1998).

[16] B. Petukhov, V. Popov, Theoretical calculation of heat exchange and frictional resistance in turbulent flow in tubes of an incompressible fluid with variable physical properties, in: High Temperature 1, 1963, pp. 69-83.

[17] M. Bhatti, R. Shah, Turbulent and transition convective heat transfer in ducts, in: S. Kakaç, R. Shah, W. Aung (Eds.), Handbook of Single-Phase Convective Heat Transfer, Wiley, New York, 1987.

[18] T. Tinker, Shell side characteristics of shell and tube heat exchangers, in: General Discussion on Heat Transfer, 1951, pp. 89-116.

[19] L. Yang, H. Tan, X. Du, Y. Yang, Thermal-flow characteristics of the new wave-finned flat tube bundles in air-cooled condensers, International Journal of Thermal Sciences 53 (2012) $166-174$.

[20] G. Gnielinski, New equation for heat and mass transfer in turbulent pipe and channel flow, International Chemical Engineering 16 (1976) 359-368.

[21] A. Premoli, D. DiFrancesco, A. Prina, A dimensionless correlation for the determination of the density of two-phase mictures, Termotecnica (Milan) 25 (1971) 17-26.

[22] M. Shah, An improved and extended general correlation for heat transfer during condensation in plain tubes, HVAC\&R Research 15 (2009) 889-913.

[23] A. Dalkilic, S. Laohalertdecha, S. Wongwises, Effect of void fraction models on the film thickness of R134a during downward condensation in a vertical smooth tube, International Communications in Heat and Mass Transfer 36 (2009) 172-179.

[24] R. Smith, Chemical Process Design and Integration, John Wiley and Sons, Inc., 2005.

[25] A. Bejan, G. Tsatsaronis, M. Moran, Thermal Design and Optimization, Wiley, New York, 1996.

[26] G. P. Towler, R. K. Sinnott, Chemical engineering design: principles, practice and economics of plant and process design, 2008. 
[30] E. Lemmon, M. Huber, M. McLinden, REFPROP - Reference Fluid Thermodynamic and Transport Properties. NIST Standard Reference Database 23, 2007.

[31] IEA, Technology Roadmap - Geothermal Heat and Power, 2011. URL:

[28] J. Andersson, A General-Purpose Software Framework for Dynamic Optimization, Phd, Aren口 123456789/418048/1/thesis_final2.pdf.

[29] A. Wächter, L. T. Biegler, On the implementation of an interior-point filter line-search algorithm for large-scale nonlinear programming, Mathematical Programming 106 (2006) 25-57.

https://www.iea.org/newsroomandevents/pressreleases/2011/june/

how-to-achieve-at-least-a-tenfold-increase-in-supply-of-geothermal-power-and-hea. html.

[32] J. Brogan, Thermopedia, 2016. URL: http://www.thermopedia.com/content/1121/.

[33] P. Subba Rao, Design Fundamentals of Shell- and - Tube Heat Exchangers, 2016. URL: https://www.studyindia.com/Pdf_Viewer/web/pdfviewer.aspx?ID=50541\& file=3281SHTE_SI1s1.pdf.

[34] ChemicalEngineering, Current Economic Trends - March, 2016. URL: http://www. chemengonline.com/current-economic-trends-march-2016/?printmode=1.

[35] ECB, US Dollar, 2016. URL: https://www.ecb.europa.eu/stats/exchange/eurofxref/ html/eurofxref-graph-usd.en.html.

[36] REN21, Renewables 2017 Global Status Report, 2017. URL: http://www.ren21.net/ wp-content/uploads/2017/06/17-8399_GSR_2017_Full_Report_0621_Opt.pdf.

[37] ENTSOE, Central collection and publication of electricity generation, transportation and consumption data and information for the pan-European market, 2016. URL: https:// transparency.entsoe.eu/. 
[38] Eurostat, Half-yearly electricity and gas prices, 2016. URL: http://ec.europa.eu/eurostat/ statistics-explained/index.php/File:Half-yearly_electricity_and_gas_prices_ (EUR).png

[39] CIA, The World Factbook, 2016. URL: https://www.cia.gov/library/publications/ the-world-factbook/fields/2207.html.

[40] Y. Dai, J. Wang, L. Gao, Parametric optimization and comparative study of organic Rankine cycle (ORC) for low grade waste heat recovery, Energy Conversion and Management 50 (2009) $576-582$.

[41] H. Chen, D. Y. Goswami, E. K. Stefanakos, A review of thermodynamic cycles and working fluids for the conversion of low-grade heat, Renewable and Sustainable Energy Reviews 14 (2010) 3059-3067. 